This is an electronic reprint of the original article. This reprint may differ from the original in pagination and typographic detail.

Author(s): Zhang, Boyang; Vos, Marita; Veijalainen, Jari; Wang, Shuaiqiang; Kotkov, Denis

Title: $\quad$ The Issue Arena of a Corporate Social Responsibility Crisis : The Volkswagen Case in Twitter

Year: $\quad 2016$

Version:

Please cite the original version:

Zhang, B., Vos, M., Veijalainen, J., Wang, S., \& Kotkov, D. (2016). The Issue Arena of a Corporate Social Responsibility Crisis : The Volkswagen Case in Twitter. Studies in Media and Communication, 4(2), 32-43. https://doi.org/10.11114/smc.v4i2.1746

All material supplied via JYX is protected by copyright and other intellectual property rights, and duplication or sale of all or part of any of the repository collections is not permitted, except that material may be duplicated by you for your research use or educational purposes in electronic or print form. You must obtain permission for any other use. Electronic or print copies may not be offered, whether for sale or otherwise to anyone who is not an authorised user. 


\title{
The Issue Arena of a Corporate Social Responsibility Crisis - The Volkswagen Case in Twitter
}

\author{
Boyang Zhang ${ }^{1,2}$, Vos Marita ${ }^{1}$, Jari Veijalainen ${ }^{2}$, Shuaiqiang Wang $^{2}$, Denis Kotkov ${ }^{2}$ \\ ${ }^{1}$ Department of Communication, University of Jyväskylä, Jyväskylä, Finland \\ ${ }^{2}$ Department of Computer Science and Information Systems, University of Jyväskylä, Jyväskylä, Finland \\ Correspondence: Boyang Zhang, Department of Computer Science and Information Systems, University of Jyväskylä, \\ Jyväskylä, Finland.
}

Received: July 18, 2016 Accepted: August 1, 2016 Online Published: August 11, 2016

doi:10.11114/smc.v4i2.1746

URL: http://dx.doi.org/10.11114/smc.v4i2.1746

\begin{abstract}
This paper explores the online debate in a corporate social responsibility crisis, where multiple actors communicate through social media, each representing different interests and views pertaining to the crisis. The study utilizes Twitter data relating to the recent case of the falsified Volkswagen diesel emissions that became public in 2015. To better understand the online interaction, use is made of issue arena theory and insights on CSR crises. The focus is on capturing the issue as it evolved over time, the actors and sentiments expressed, and the responses of the organization. The findings show that after the case became public, the emissions issue received massive attention in Twitter. Sentiment analysis showed high negative peaks following news that revealed details about the case. Among the most active external accounts, the group labeled General and business news was the most critical. The replies posted by Volkswagen on@VW were few, providing explanations and links. Volkswagen websites were used to disseminate information, but the case was also heavily discussed in a large number of independent discussion platforms, blogs and wikis. The findings demonstrate that CSR challenges can result in a crisis of a long duration marked by strongly expressed sentiments and a wide diversity in the views of different stakeholder groups. The focal organization reacted to the events with the twin strategies of apology and compensation. The study shows the risk of CSR challenges resulting in crises in cases where stakeholder expectations have been created but not met, generating loss of reputation.
\end{abstract}

Keywords: corporate social responsibility, crisis communication, issue arena, social media, Volkswagen

\section{Introduction}

The effects of organizational crises have received attention in sustainability policymaking by organizations. Corporate Social Responsibility (CSR) has importance for benefitting society beyond the profit interests of companies (Coombs \& Holladay, 2015). With the evolution of CSR at the organizational level, CSR has been raised to a performance-oriented management perspective in organizations (Lee, 2008). A considerable amount of research has been carried out on organizational CSR, while relatively less attention has been paid to online CSR challenges. It is of interest to further investigate a case where a CSR challenge became a crisis, as suggested by Coombs and Holladay (2015) who argue that CSR communication raises expectations and, therefore, can also be seen as a risk.

This research evaluates interaction as it evolves in issue arenas, understood as places where multiple actors discuss issues they have a stake in (Luoma-aho et al., 2010). These are, by other authors, also called rhetorical arenas for multi-vocal communication (Frandsen \& Johansen, 2008; Coombs \& Holladay, 2014). Social media provide platforms where such an exchange of views involving different stakeholder groups can take place.

The study uses Twitter data to gain insight into the evolving debate, the sentiments of the tweets exchanged about the issue, the most active accounts, and sites of interaction by the focal organization.

This article reports on a case study of the Volkswagen Group emission scandal that broke in 2015. The actions taken by Volkswagen are assessed from the perspective of CSR, as irresponsible actions damage reputation and consumer trust. The interests of internal stakeholders and highly competitive business targets may have led to the events precipitating the crisis. 


\section{Theoretical Background}

This section reviews the importance of multi-actor online interaction in the social media literature. Thus far, few studies have attempted to explain online stakeholder interaction in CSR crises. This paper attempts to enhance understanding of online discussion as it evolves in the case of an organization faced by a CSR challenge. Social media debate tends to show high activity levels and the expression of strong sentiments during such organizational crises.

\subsection{Evolving CSR Issues in Social Media}

Organizational issues are topics debated in public that relate to a focal organization, which in turn may use issues management to track such topics so as to more effectively interact regarding them. Online issues are widely recognized as formed by social media discourse (Henderson \& Bowley, 2010; Keim, 2011; Pavitt, 2012), and organizations have begun to note the importance of monitoring social media use (Sedereviciute \& Valentini, 2011), as a basis for constructing communication strategies to connect with the different stakeholders (Zhang \& Vos, 2014).

Social media sites support the fast diffusion of information by allowing instant publication in various formats (Kombol, 2014). Organizations should be aware that negative issues in particular tend to diffuse virally online, especially when the negative contents relate to problems caused by socially irresponsible organizations (Lee, Oh \& Kim, 2013). A crisis may arise when an organization is scrutinized critically by its stakeholders (Pang, Hassan \& Chong, 2014), having a profound impact on the organization's reputation (Sriramesh, Rivera-Sánchez \& Soriano, 2013). Some crises have been triggered by a huge amount of online user-based messages, when accusations against a focal organization stimulated viral spreading of negative issues (Pang et al., 2014).

Accordingly, Dekay (2012) recommends serious consideration of the views of different audiences, such as fans and hater groups, with fans in the role of defender of the brand and haters attacking it. For this purpose, Luoma-aho (2015) introduced, next to the concept of stakeholder, the concepts faithholder and hateholder. Research on such groups can help evaluate the impact of social media on social legitimacy (Bonsón \& Ratkai, 2013). For example, a study showed that loyal customers of Toyota enhanced brand reputation on social media sites during the recall crisis in 2009 (Byrd, 2012).

Curley and Noormohamed (2014, p. 62) defined CSR as "a trend in corporate policy which serves as a self-regulatory guide to socially and environmentally responsible business practices". CSR focuses on balancing social responsibilities with profitable organizational activities, and is based on sensemaking, negotiations and dialogue (Schultz \& Wehmeier, 2010). The search for social legitimacy is consistent with the disclosure of CSR (Bonsón \& Ratkai, 2013). Legitimacy is seen as congruence between the corporate CSR agenda and stakeholders' social expectations (Colleoni, 2013), that is, a balance between company interests and the common good. As CSR comprises several themes, Bonson and Ratkai (2013) categorized it into major points of attention, including environmental, social and financial aspects, and governance. Similarly, Kolk (2016) emphasized the environment, ethics, rights and responsibilities, as well as poverty and sustainable development. Organizations that act indifferently to the expectations of stakeholders regarding its CSR can harm their reputation (Pavitt, 2012). Generally, CSR activities have developed from primarily using traditional media to including social media (Sharma, 2012), for example, by participating in Twitter, Facebook, YouTube, Google+, and WhatsApp.

Transparency can underpin organizational long-term commitment to CSR (Curley \& Noormohamed, 2014), whereas unfavourable hidden actions by organizations are easily revealed publicly with both immediacy and extensive coverage (Pavitt, 2012). Transparency benefits from the synchronization of content developed for different channels, taking both traditional and social media into account to enhance stakeholder engagement (Diers \& Donohue, 2013). The content of organizational messages along with channel selection, often follows the intentions of the organization (Koenig, 2014), but this content needs first and foremost to relate to stakeholders' voices as expressed in social media and other channels. As Pavitt (2012) suggests, here the corporate ownership of social media platforms and the general lack of control over their content should be taken into consideration.

CSR activities have commonly been seen as promoting organizations' competitive advantages. Recently, however, Coombs \& Holladay (2015) introduced the concept of CSR challenge and postulated that CSR communication can regarded as a potential crisis risk (Coombs \& Holladay, 2015). Organizations with highly creditable CSR themes find favor among stakeholders online (Lee et al., 2013), and as a result their CSR communication may raise public expectations (Schultz \& Wehmeier, 2010). When reality does not meet such expectations, CSR may switch from being an advantage to being a risk, at worst resulting in negative sentiments and considerable reputation damage. In this way, a triggering event such as negative information becoming public, may turn a CSR challenge into a profound organizational crisis. In other words, CSR claims cannot be made lightly, as they create additional responsibilities and expectations. 


\subsection{Multiple Actors in Issue Arena Communication}

In social media, various stakeholders engage in debate on organizational issues, and hence nowadays organizations also utilize social media for communication purposes (Bonsón \& Ratkai, 2013). Compared to traditional media, a unique characteristic of social media is its potential for multi-actor interaction, which makes it even more important that organizations are aware of stakeholders' sentiments (Byrd, 2012).

Issue arena theory was developed with a fast-changing environment, and especially virtual media, in mind (Luoma-aho \& Vos, 2010). It aims at understanding the complexity of issue debate. Online interaction on issues is co-created by various actors with different interests and points of view (Vos, Schoemaker \& Luoma-aho, 2014). Monitoring activities can amplify the voices of various external stakeholders when concerns about the performance of the focal organization begin to arise. In social networks in particular, the roles of influentials such as bloggers and scholars are interesting in this respect (Van den Hazel, Keune, Randall, Yang, Ludlow \& Bartonova, 2012). Similarly, public and private organizations other than the focal organization may play an essential role in the debate on an organizational issue.

To understand the course of a particular issue debate, next to the actors involved, the places of interaction also need attention (Vos et al., 2014), as differences between the different social media have to be taken into account. For example, Twitter is the social media tool most commonly used to disseminate news information, as it is easy for anyone to follow a Twitter account. This has resulted in influential users with millions of followers (Sharma, 2012), without any need for the two-way acquaintanceships required by other social media tools, such as WhatsApp (Sedereviciute \& Valentini, 2011). Tweets have a limited number of characters and, therefore, redirect links are often included in them to enable access to background information on, for example, YouTube or websites (Sriramesh et al., 2013).

In Twitter, the co-creation of the discourse on an issue occurs when different actors address different aspects of the debate. Tweets can be characterized as microblogs that enable fast realtime exchange of information (Zhang \& Vos, 2015), and hence interactivity in Twitter refers to fast retweeting and replying, often involving large numbers of users (Kwak, Lee, Park \& Moon, 2010). Twitter is suitable for realtime news publishing from different points of view, including eye-witness reports. It can be seen as a weak-ties network with active user interaction, whereas social networks such as Facebook are strong-ties social networks with more personal information exchange and less public discussion (Fischer \& Reuber, 2011). Moreover, users of Twitter are free to follow others whereas, for example, WhatsApp is a messaging app in a closed friendship environment. All of this, including the fact that Twitter has an archive function, meaning that tweet collection can go back in time, explains why research on the spread of issues in social media often focuses on Twitter, especially when it concerns crises (e.g. Li, Vishwanath \& Rao, 2014).

It is important for sustainable development that an organization is able to foster trust in its diverse stakeholders (Byrd, 2012), and listen not only to the voices of stakeholders who are financially interested in the organization, but also to those of all the other relevant stakeholders (Pavitt, 2012). This may enable an organization to prevent or survive a crisis (Byrd, 2012). As a lack of transparency in an organization can trigger critical misunderstandings, organizations also need to pay attention to the interaction between employees in different departments. Internal communication with managerial support can enhance awareness of CSR within an organization. Among an organization's external stakeholder groups, publics are seen as citizen audiences who help the organization to keep in mind the importance of the common good (Sriramesh et al., 2013), alongside other external stakeholder groups such as clients and shareholders with their own interests and points of view.

\subsection{Crisis Response and Interactivity}

Responding to organizational crises includes reduction of (further) damage to stakeholders, and crisis communication aimed at corporate image repair (e.g. Benoit, 1994). Various communication strategies may be used. Different types of response strategies have been identified in the Situational Crisis Communication Theory (SCCT), including attack the accuser, denial, scapegoat, excuse, justification, compensation, and apology (Coombs, 2007). SCCT links recommended strategies to different crisis situations. In a complex crisis multiple response strategies may be needed.

In crisis communication and issues management, rather than reacting to stakeholder views, a proactive attitude is recommended, where the organization leads rather than follows in the interaction, for example, by explaining events in a timely way and preferably before they have been brought to public attention by others (e.g. Heath \& Nelson, 1986; Coombs, 2007). Online interaction by the focal organization can reveal its chosen response strategies.

Organizations monitor the discourse to be able to reply, which is also increasingly expected by users. The direct engagement between an organization and its stakeholders in a social media debate demonstrates the dynamics of stakeholder relations (Fieseler \& Fleck, 2013). Among the places of interaction, the official social media sites of the focal organization merit special attention (Byrd, 2012; Henderson \& Bowley, 2010). Social media offer good possibilities to facilitate two-way communication (Wright \& Hinson, 2009); however, these remain underused as 
one-way information tends mainly to be posted (Coombs, Falkheimer, Heide, \& Young, 2015). Such potential for dialogue and an "architecture of listening" needs to be used to regain trust and rebuild relations with stakeholders (Macnamara, 2016). It has been suggested that two-way communication is critical on the web and that, for example, companies that are active online receive fewer negative mentions in Tweets but only if they engage in real dialogue (Wigley \& Lewis, 2012).

Recommendations for interaction on issues emphasize that dialogue-related strategies are adequate to cope with unfolding concertative interaction (Romenti, Murtarelli \& Valentini, 2014), such as in crisis situations, where the voices of online users can be catagorized into separate agendas for the formulation of specific crisis response strategies. Collaborative and active online interaction may help to build and maintain relationships between an organization and its stakeholders characterized by high levels of trust and transparency (Cox \& McLeod, 2014), as social media tools may facilitate both bonding with close ones and bridging of weak links (Chang, 2015).

\section{Research Method}

This section opens with a brief case description. Next, the research questions are listed, followed by the collection of the Twitter data set and the analytical methods applied.

\subsection{Case Description}

The Volkswagen emission scandal triggered a heated debated on September $18^{\text {th }}$, 2015. The United States Environmental Protection Agency (EPA), which aims at the safeguarding of human health and environment, accused the Volkswagen Group of equipping specific models of diesel vehicles with defeat software designed to enable them to successfully pass emission tests in a laboratory or vehicle inspection station, whereas under normal driving conditions the levels of nitrogen oxide pollutants were in some cases up to 40 times higher than the legal limit, violating the Clean Air Act. and resulting in the manufacturer being fined of several billions of U.S. dollars. On the global market, approximately 11 million cars were equipped with the same defeat software. After the case became public, the Volkswagen Group reacted by admitting the deception and making public apologies. Michael Horn, then CEO of the Volkswagen Group of America was replaced, and Christine Hohmann-Dennhardt added as board member for Integrity and Legal Affairs. The company paid compensation to car owners in the U.S., and planned a massive recall in 2016 to correct the problem in affected cars worldwide. The image and reputation of the Volkswagen Group was severely affected by the emissions scandal (Zhang, Veijalainen \& Kotkov, 2016), with sales and stock prices dropping sharply. Volkwagen had been seeking entry to the U.S. market for its diesel automobiles, calling them 'clean diesel' on account of their low carbon dioxide emissions. However, the ceiling on nitrogen oxide emissions was even lower in the U.S. than in Europe. The company had been nominated for a CSR award before the case became public. Emission test results have raised suspicions before, but in this case software had been added to defeat the test conditions and artificially maintain the emission levels registered below the permitted limits.

\subsection{Research Questions}

This case study was conducted to demonstrate the complexity of CSR challenges and related crisis discourse in a multi-actor online environment. The Volkswagen emission scandal developed over a long period of time and shows how multiple interests joint the online debate. The research questions were designed to clarify the course of the debate, sentiments expressed, active accounts and replies by the focal company.

RQ 1: How did the debate on the Volkswagen emissions evolve over time? (This question concerned the fluctuation in the numbers of tweets about the issue over time, as well as their sentiments.)

RQ 2: How can the most active external actors be characterized? (This related to the most active accounts, how these are distributed in stakeholder groups, and the sentiments expressed in the tweets sent by these groups.)

RQ 3: What response strategy can be deduced from the replies by Volkswagen? (This focused on the interaction by Volkswagen, and in particular the replies sent via Twitter.)

\subsection{Collection of Twitter Data}

The data set for this study mostly relies on Twitter. As already discussed, Twitter is one of the largest online social network platforms and the social media tool most commonly used to disseminate news information. It allows researchers to retrace realtime interaction over a period of time, to follow how an issue evolved. However, in addition, Facebook and some online discussion platforms were also looked at and the results are reported here in brief.

The Twitter data set was collected by relying on the Twitter Streaming API. The software used was Tweepy v2.7 and Tweepy v3.5 (see http://www.tweepy.org/). Over time, different selection predicates were used, as the most relevant keywords changed over time. The first selection predicate was stream.filter (track=['vw volkswagen', 'scandal', 'reputation', 'diesel', 'software']). Very soon the hashtags \#dieselgate and \#vwgate emerged in tweets that referred to the 
crisis. Therefore, those hashtags were added and the stream.filter (track=['vw', 'volkswagen', 'VWgate', 'dieselgate']) briefly used. During autumn 2015, the term "emission fraud" also emerged. At the end of September, the selection predicate was changed to the stream.filter (track=['vw', 'VW', 'volkswagen', 'Volkswagen' 'scandal', 'reputation', 'dieselgate', 'vwgate', 'emission', 'fraud']). The stream.filter (track=['vw', 'volkswagen', 'scandal', 'reputation', 'diesel', 'software', 'vwgate', 'emission', 'fraud']) was also used to test the capture power in parallel. From December 2015 onward, the following selection predicate was used: stream.filter (track=['vw', 'VW', 'volkswagen', 'Volkswagen', 'scandal', 'reputation', 'dieselgate', 'vwgate', 'emission', 'fraud']).

The number of different tweets amounted to over 13 million between September $23^{\text {rd }}, 2015$ and June $23^{\text {rd }}, 2016$ in the raw data set. Many non-relevant tweets were found among those collected, including advertisements, sales information, synonyms, tweets in German and other languages, and so on. Therefore, as a next step, a filtering process was conducted to focus on the tweets in English where the text contained words included in the following predicate: (@VW or @ Volkswagen) or (('olkswagen' or 'vw' or 'EA189' or 'VW') and ('oftware' or 'candal' or 'iesel' or 'gate' or 'pollut' or 'raud' or 'fine' or 'stock' or 'mission' or 'heating' or 'CEO' or 'share' or 'hief')).

The data set contained a total of roughly $1,046,000$ qualified and thus relevant tweets by June $23^{\text {rd }}, 2016$. The present results are based on this data set or a subset of it. The data collection from September $23^{\text {rd }}, 2015$ to February $11^{\text {th }}, 2016$ was almost continuous; thereafter, data were not gathered as regularly. Gaps of a few weeks occur and no data were collected during May 2016. The collection was restarted on June $18^{\text {th }}$ and reporting terminated on June $23^{\text {rd }}, 2016$.

\subsection{Data Analysis}

Several quantitative textual analyses were conducted to capture the complexity of the case, and enhance the accuracy and reliability of the results. To gain insight into how the Volkswagen emissions issue evolved over time, a frequency graphic of tweets during the research period was constructed. Next, a sentiment analysis of the tweets during the research period was conducted. This was done by scoring the textual content of the tweets, customizing the procedure of R-studio (http://www.r-bloggers.com/twitter-sentiment-analysis-with-r/). The latter provided a way of thinking, but several adjustments were made to meet the requirements of the case data, including the readline and timing techniques. The inclusion criteria were that that the language of the tweets is English and the Boolean value of each tweet is true. The presentation of the sentiment analysis focuses on the positive and negative scores.

To better understand the active actors other than the focal organization, the 15 most active external accounts were identified based on the number of related tweets, not including Volkswagen-verified accounts or accounts controlled by the company. The data were filtered on June $23^{\text {rd }}, 2016$. The accounts were examined, to provide a brief description and, based on the latter, grouped. Next, a sentiment analysis was conducted to characterize the tweets of the most active accounts. The tweets were scored, again customizing the procedure of R-studio.

To investigate the replies by Volkswagen, the Twitter accounts were listed and the account @VW was selected, as this had the most followers, showed first in a Google search, most often had a bearing on the case and was the most interactive. The number of replies was noted and a Word Cloud, using https://www.jasondavies.com/wordcloud/, was made to gain an initial insight into the content of the replies. Next, the replies were categorized by grouping similar elements, using the keyword search, into one category.

Additionally, a brief analysis was conducted of the Volkswagen Facebook chat platform to see how many replies Volkswagen provided there, using Graph API (https://developers.facebook.com/docs/graph-api) with a Java program to filter relevant comments plus replies. In addition, a Google Search (www.google.com), testing several key words, was conducted on November $9^{\text {th }}, 2015$ to gain an idea of the extent to which other types of social media, such as forums and blogs independent from the focal company, were being used for interaction about the Volkswagen emissions issue.

\section{Findings}

First, the numbers of tweets in the Twitter data set are shown by date. Second, the results of the sentiment analysis of tweets, providing an insight into the tone of voice of the tweets over time, are presented. Third, the results of the analysis of active accounts, showing who were active in Twitter, are presented. Fourth, the replies by Volkswagen are discussed.

\subsection{The Evolving Crisis as Shown in Twitter}

Using the data set collected a cure graph was constructed to show the fluctuation in the volume of tweets pertaining to the case during the research period. Figure 1 shows the changes in volume from September $23^{\text {rd }}, 2015$ to April $8^{\text {th }}, 2016$. 


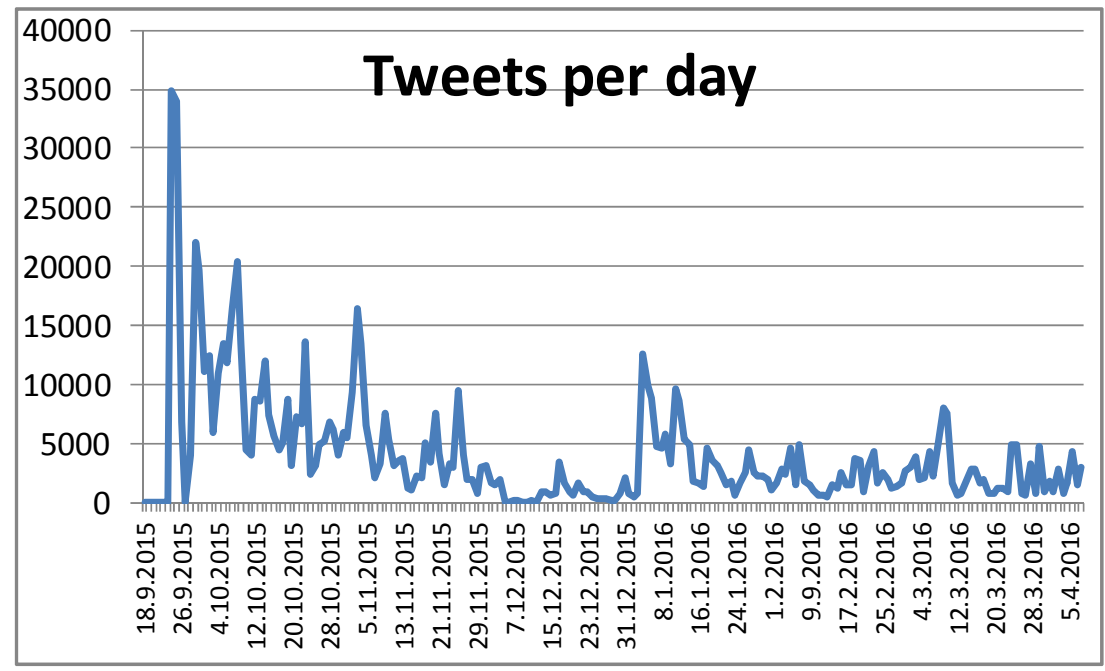

Figure 1. Twitter data set collection

On September $24^{\text {th }}, 2015$ the number of tweets rose sharply, reaching 34,000-35,000 related tweets on the next day. After the news about the case became public, the numbers of tweets per day remained relatively high for more than a month. (The low number on September $26^{\text {th }}, 2015$ was caused by a server crash lasting 48 hours which caused a minor interruption in the data collection.) As might be expected, after the initial peak the figure shows a steady decrease. A further peak of 21,956 tweets occurs on September $29^{\text {th }}$, and another of 20,343 tweets on October $8^{\text {th }}$. Thereafter, the number of daily tweets remains below 20,000. However, it is noticeable that the Volkswagen emissions issue remains active over a long period. This indivates the severity of the crisis for Volkswagen.

To better understand the development of sentiments over time, an overall sentiment analysis was conducted. The results are shown in Figure 2.

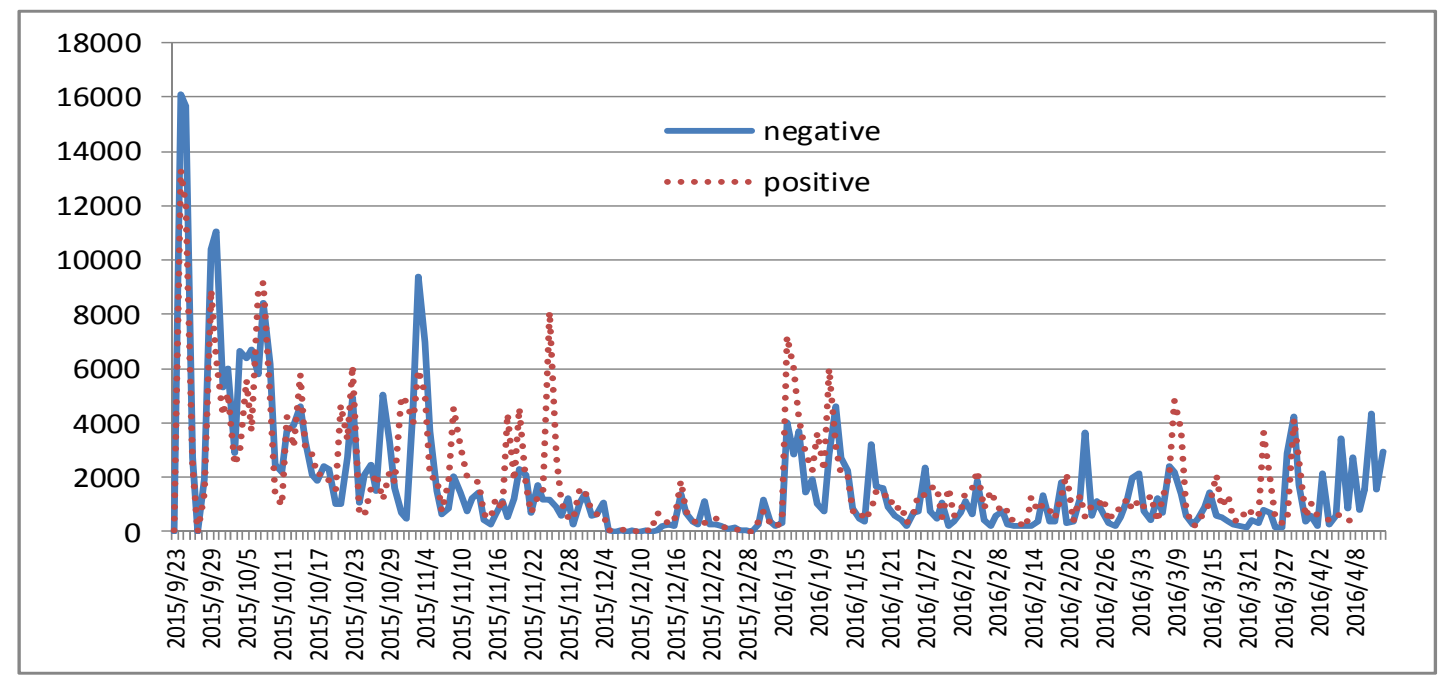

Figure 2. Sentiment analysis of Tweets over time

Figure 2 shows that in the first days of the crisis many negative tweets were posted (aspects of CSR aspects were often referred to in the tweets and disappointment showed). The negative peaks seem to follow the news on the case, until the interest in the item in question died out. For example, a negative sentiments peak occurs on November $3^{\text {rd }}, 2015$, one day after the announcement that the EPA had found more Volkswagen models with 3.0 TDI engines that had the defeat software. New negative sentiments peaks arose as more details became known, for example following the apologies and confirmation of the facts by CEO Winterkorn on September $22^{\text {nd }}, 2015$.

Positive sentiment peaks are also present, for example after apologies and clarifications were given by the new CEO Müller on January $1^{\text {st }}, 2016$. In general, it should be noted that the sentiment analysis may over-represent positive sentiments, as it is based on the words used (e.g. "bad" or "good") and classifies many statements (such as "violating 
the law") as neutral. Moreover, negative tweets such as personal complaints may be retweeted less often than neutral news feeds or positive tweets including recommendations.

\subsection{Active Stakeholder Accounts}

A multitude of accounts on Twitter, representing a diversity of interests, including, for example, retailers, news media, and consultancies, co-created a voluminous multi-actor discourse on the Volkswagen emissions issue. An actor analysis was performed to find out which types of stakeholders were most active in Twitter. The focus was on external accounts, excluding any verified accounts of Volkwagen or accounts controlled by the focal company. The 15 most active external accounts for this topic are listed in Table 1, ranked according to the numbers of tweets sent during the research period.

Table 1. Most active external accounts

\begin{tabular}{llr}
\hline $\begin{array}{l}\text { Most active external accounts } \\
\text { (31.05.2016) }\end{array}$ & Links & $\begin{array}{l}\text { Number of } \\
\text { tweets }\end{array}$ \\
\hline 1. wallpapers7 & https://twitter.com/wallpapers7 & 2494 \\
2. Sufiy & https://twitter.com/Sufiy & 1721 \\
3. IPandHuf & https://twitter.com//PandHuf & 1576 \\
4. OnlineCarReview & https://twitter.com/OnlineCarReview & 1479 \\
5. kirillklip & https://twitter.com//kirillklip & 1142 \\
6. AutoNewsBot & https://twitter.com/AutoNewsBot & 1124 \\
7. pautoappraisers & https://twitter.com/pautoappraisers & 1079 \\
8. MoneyNews24h & https://twitter.com/MoneyNews24h & 952 \\
9. UsedCars4sa & https://twitter.com/UsedCars4sa & 712 \\
10. ooyuzaudi & https://twitter.com/ooyuzaudi & 709 \\
11. InvestingLatest & https://twitter.com/InvestingLatest & 700 \\
12. RealTimeHack & https://twitter.com/RealTimeHack & 700 \\
13. Autotestdrivers & https://twitter.com/Autotestdrivers & 679 \\
14. testdrivernews & https://twitter.com/testdrivernews & 678 \\
15. neils_rt & https://twitter.com/neils_rt & 665 \\
\hline
\end{tabular}

Each of the top 15 active external accounts for the Volkswagen emissions issue has posted a considerable number of tweets during the research period. To further analyze these accounts, a brief description of each account was given. Next, similar accounts were grouped and labeled (see Table 2).

Table 2. Groups of the most active external accounts

\begin{tabular}{|c|c|c|c|}
\hline Automotive organizations: & Consultancies: & Online car journals: & General and business news: \\
\hline $\begin{array}{l}\text { UsedCars4sa (used cars for } \\
\text { sale in South Africa) }\end{array}$ & (investment & $\begin{array}{l}\text { IPandHuf (car news and } \\
\text { technology) }\end{array}$ & wallpapers7 (global news) \\
\hline $\begin{array}{l}\text { Autotestdrivers (automotive } \\
\text { test drivers) }\end{array}$ & $\begin{array}{l}\text { pautoappraisers } \\
\text { appraisals) }\end{array}$ & $\begin{array}{l}\text { OnlineCarReview (new } \\
\text { cars) }\end{array}$ & Sufiy (investment news) \\
\hline $\begin{array}{l}\text { testdrivernews (automotive } \\
\text { testing) }\end{array}$ & $\begin{array}{l}\text { InvestingLatest (insights } \\
\text { for investors) }\end{array}$ & $\begin{array}{l}\text { AutoNewsBot (up to date } \\
\text { automobtive news) }\end{array}$ & $\begin{array}{l}\text { MoneyNews } 24 \mathrm{~h} \text { (financial } \\
\text { news) }\end{array}$ \\
\hline & neils_rt (consultancy info) & ooyuzaudi (car news) & $\begin{array}{l}\text { RealTimeHack } \\
\text { services) }\end{array}$ \\
\hline
\end{tabular}

To investigate the tone of voice of the messages posted by the top active accounts, a sentiment analysis was implemented. After listing the sentiment scores for the 15 most active accounts, we collated the results per group. The findings are presented in a stakeholder map (see Figure 3) with the positive and negative sentiment scores as axes, showing clear differences between the groups.

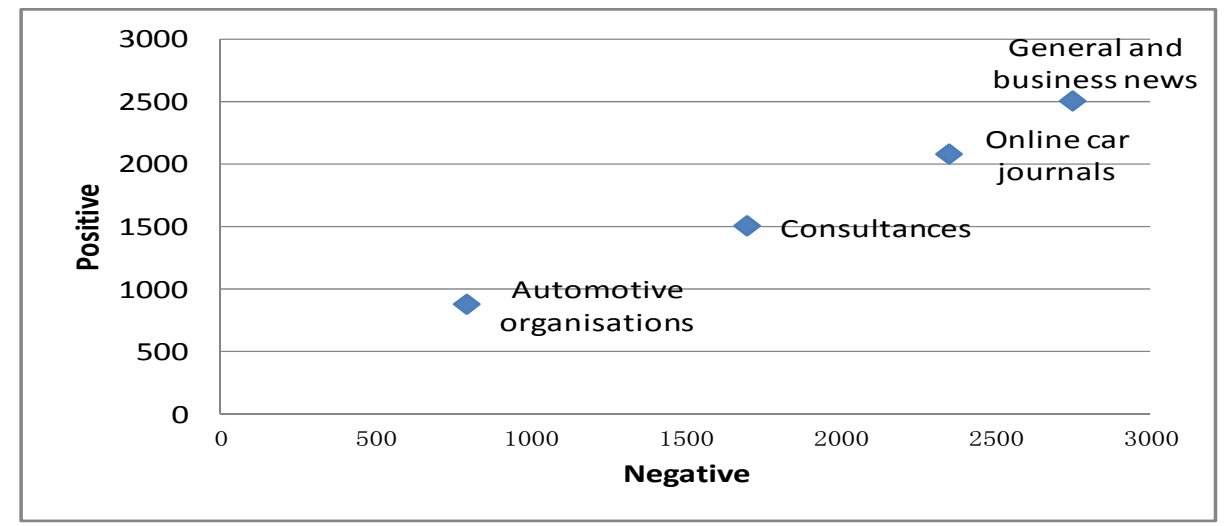

Figure 3. Map showing the positive and negative sentiment scores of the groups 
Negative sentiments occur most in the group General business news, and positive scores most in the group Automotive organizations. Only a few accounts show high numbers of both positive and negative comments, but in the fall of 2015 this was the case for wallpapers7, which focuses on information for shareholders.

The General and business news accounts include many critical comments, which can be understood in the light of the financial repercussions of this crisis. For example, @wallpapers7 posted on September 25 $5^{\text {th }}, 2015$ : "http://t.co/ReIBXg0QpV \#Hash4Tags RT rodbishop15: \#Pensioners who have had their funds invested in \#VW shares should be fuming. \#Volkswaglu2026"; and "http://t.co/ReIBXg0QpV \#Hash4Tags 27 US states plan to subpoena \#VW via Business http://t.co/UMjgR42Oup http://t.co/Dh1sT0SRKK".

The group of Automotive organizations posted many statements with neutral or positive sentiments. For example, on October 7" th 2015, @UsedCar4sa posted "'VW Group CEO Matthias Muller Confident About Overcoming

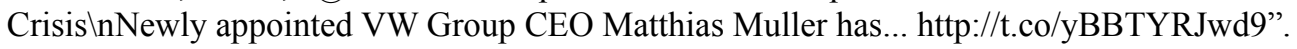

For the 15 most active external accounts combined, negative scores form $52 \%$ of the total sentiments measured, whereas the corresponding proportion of the overall results in Twitter, which also included accounts owned by the Volkswagen Group, was $48 \%$. Thus, the most active external accounts show, like the overall Twitter results, a high level of negative sentiments.

\subsection{Social Media Interaction by the Focal Organization}

To understand the response of the focal organization, @VW, the Volkswagen U.S. verified account with approx. 450K followers in Twitter, the number of replies was calculated. The result showed that, in total 581 tweets were posted during the whole research period by @VW, 499 were replies.

To gain an initial insight into the content of the tweeted replies by @VW, we used Word Cloud. The result is shown in Figure 4.

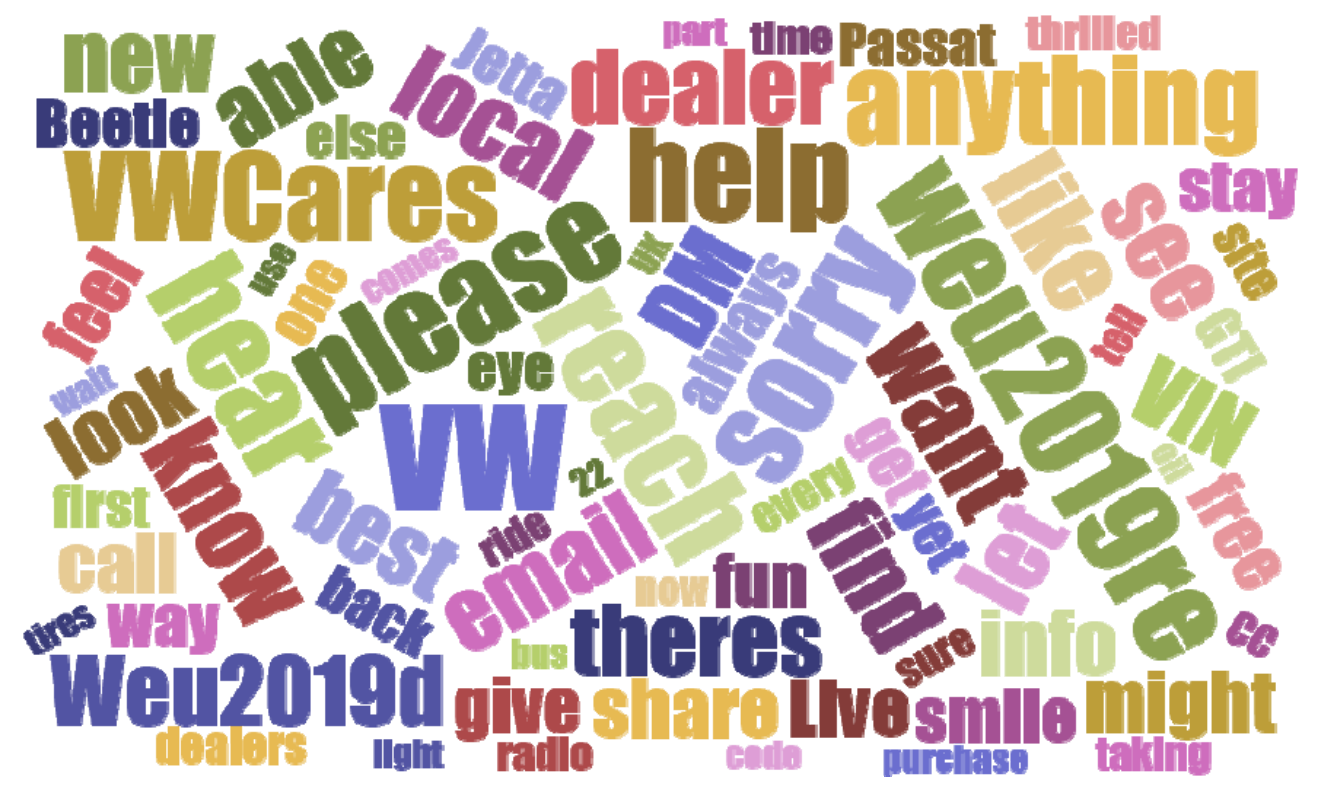

Figure 4. Word cloud of replies by @ VW replies

Words like "sorry" stand out in the word cloud constructed from the replies. Some examples of the tweeted replies from @ VW follow.

@tylapper: "You can Live Chat with us at https://t.co/elor7ebi6a or give us a call at 800-822-8987."

@Dezlboy: "We"d be happy to look and see if there are any recalls on your VW. Please reach out to us at https://t.co/elor7ebi6a so we can check."

To get more insight into the content of the 499 replies, some of which combined two types of reply, we categorized them. The following 4 types of reply were found: (a) acknowledgements or greetings in various contexts, such as welcome or thank you (303 replies); (b) redirecting people to other sites by links (268 replies); (c) apology making and/or explanatory (167 replies); and (d) referring to services ( 86 replies). However, it should be noted that total number of replies in the Twitter Account @VW was not high. 
Although other social media were outside the focus of this study, we collected some additional data to see if these matched the picture gained from Twitter. We found, similarly, that the Facebook page of Volkswagen did not show many replies by the Volkswagen Group (https://www.facebook.com/VW/?brand_redir=DISABLE). We collected in total 60 posts published from September $17^{\text {th }}$, 2015 until April 11 ${ }^{\text {th }}, 2016$, along with 17,357 comments and 9,553 replies that related to the posts. However, very few of these replies were by Volkswagen. In fact, for the whole research period of 203 days only 103 replies by Volkswagen were found. Thus, Volkswagen was not very active in replying on its Facebook page either.

Mainly, Volkswagen issued information through its websites. Six Volkswagen websites were found that related to the emissions issue and, for example, the recalls. The official VW websites have recently been studied by Zhang et al. (2016). They found less interaction with the public than reported here concerning Twitter or Facebook, as the web focus was on informing about solutions, customer services and press releases.

Online, the Volkswagen emissions issue was discussed on many other sites. A Google search yielded, next to many news-related items (for example, "VW sinks deeper into the mire"; "The scandal explained"), at least three highly active discussion platforms, and six blogs or wikis. As expected, the Internet showed multi-actor discussion, with many actors posting messages on many different platforms, and deeper interaction among some users on fewer discussion platforms. The latter concerned the immorality of cheating in the emission tests, trends in emission norms, and consequences for citizens and industry. Examples are a blog titled "VW deception not an isolated case and not just the auto industry", a wiki "VW TDI diesel emissions test cheating FAQ and timeline", and a discussion chat platform on "VW's emission scandal over the TDI engines".

Online, people discussed this case on many different platforms, creating an even more voluminous discourse than the messages collected solely from Twitter, which demonstrates, on the one hand, the challenging nature of such issues for the focal organization and, on the other hand, how much the Volkswagen emissions issue meant to stakeholders.

\section{Discussion and Conclusion}

The findings underline the importance of Corporate Social Responsibility (CSR) in the sustainable development policies of organizations, but also the risk of CSR challenges resulting in crises where stakeholder expectations have been created but not met, generating loss of reputation.

After the issue of the falsified Volkswagen emissions became public, it received massive attention in Twitter. The sentiment analysis showed high negative peaks following news items that revealed details on the case, but positive sentiments were also present depending on the interests of the accounts. The 15 most active accounts showed divergent sentiment scores, the group General and business news being the most critical. The replies posted on @VW were not many; they mostly contained greetings, explanations and links. Several Volkswagen websites were used to provide information, for example, which vehicles were affected and when repairs could be expected, but the Volkswagen emissions issue also continued to be heavily discussed in a large number of independent discussion platforms, blogs and wikis.

As an example of a CSR Challenge, the issue was characterized by a long period of strong sentiments. This accords with the approach by Coombs and Holladay (2015), who noted that when behavior by a company with a previously positive CSR reputation is confirmed to be socially irresponsible, this can lead to heated public debate. In the case of the Volkswagen emissions scandal, the CSR-based challenge began after it became known that defeat software had been used to falsify emission test readings, making diesel cars appear less polluting than they were. The earlier claim by Volkswagen to be marketing clean diesel cars now seemed greenwashing, and thus had strong potential for reputation damage.

The Volkswagen Group had earlier been known for fuel-efficient cars and engagement in CSR. Scholars (e.g. Schultz \& Wehmeier, 2010) agree that when an organization engages in CSR communication it may encounter raised public expectations. It can be concluded that, because the emissions scandal violated stakeholder expectations regarding fair and sustainable business policies, it led directly to a CSR crisis. Thus, Volkswagen AG's stock was immediately removed from the Dow Jones Sustainability indexes after the news about the emissions defeat software broke on September $18^{\text {th }}, 2015$.

The CSR challenge was also characterized by the involvement of many different actors in the online debate. The discourse showed the diversity of the positions taken and sentiments expressed by the main active accounts. This may typify CSR-related issues, as CSR policies seek to take different interest groups into account, bridging these through dialogue where possible (Schultz \& Wehmeier, 2010). In the Volkswagen case, we noted different views by actors in the car industry and those in the news media. Individual tweets also reflected the positions of faith- and hateholders (Luoma-aho, 2015). The long duration of the issue can be explained by the fact that this CSR challenge led to legal and 
administrative procedures resulting in a series of news events that the stakeholder groups in turn discussed online, showing continued strong sentiments over a long period with peaks when new information became public.

Finally, the response strategies of this example of a CSR challenge included types mentioned in the SCCT literature. It is no wonder that a clear failure to deliver CSR promises is answered by voicing apologies and compensation. Some of the reluctance to engage in these, as noted above, may relate to the severity of the financial and legal consequences. The aim of crisis response strategies is to enable the organization to recover quickly from a crisis and prevent similar crises in the future. In the case of the Volkswagen emissions issue discussed here, the company's response strategy could have been more proactive. In the period before the defeat software became public, Volkswagen had initially denied research results that had shown high emissions. There also were tweets rumouring that evidence had been deleted.

After the case became public, the Volkswagen strategy can be characterized, following the types identified in the Situational Crisis Communication Theory (Coombs, 2007), as making the recommended apology along with compensation, although so far only to U.S. car owners. Many European car owners are still waiting for their cars to be recalled, and uncertain about compensation. While Volkswagen was active in its communications, this was only after the case had become public. Moreover, the company focused mainly on its own websites, posting relatively few replies in social media. This may partially explain the many negative sentiments expressed in the online environment. Moreover, it should be noted that the Volkswagen emissions issue has not yet fully been resolved.

At the shareholder meeting on June $22^{\text {nd }}, 2016$, heated discussions took place on the future of the company, one potential future direction being an increase in the production of electric vehicles. On that same day, ChinaBootik tweeted "Volkswagen places question mark over future of diesel technology via / $/ \mathrm{r} /$ Futurology https://t.co/sKL6K5vMWD" and, for example, ZackaryCox65 tweeted "Volkswagen to launch more electric cars after diesel scandal - https://t.co/sCSErWq844". Therefore, the case studied here, in fact, continues to live on, as does the broader issue of vehicle emissions in relation to the future of the car industry.

This study compiled and investigated a large amount a data to clarify social media debate on a CSR challenge. Although the volume of data was large, a limitation is that the study focused mostly on just one social media tool, Twitter. It has been suggested that different types of social media can function as different sub-arenas (Coombs \& Holladay, 2014). However, additional data obtained from Facebook supported the conclusions based on the Twitter data.

The present analyses provide an overview of this heavily debated issue, showing how the crisis evolved over time, and providing insights into the sentiments expressed, the most active actors, and replies by the focal company. Future research could further analyze other cases where CSR challenges became a crisis, as this type of crisis has the potential to go viral, creating high sentiment scores and engaging a diversity of stakeholder groups.

Taken together, the case findings illustrate that CSR may become a risk if organizations are not able to fulfil their promises (Coombs \& Holladay, 2015). The findings are also a reminder of the vast numbers of messages that are exchanged in such cases, as nowadays social media function as platforms for the co-creation of discourse by multiple actors on issues that they have a stake in. Monitoring such issues and responding to stakeholder needs and views is challenging. CSR challenges form an issue arena with complex multi-stakeholder interaction. It can be concluded that communication strategies need to take into account different types of crisis and organizational contexts, including CSR challenges. Moreover, on the topic of CSR challenges, CSR scholars may learn from insights provided by crisis communication scholars, and vice versa.

\section{Acknowledgements}

This study has in part received funding from the Academy of Finland, grant number 268078 (MineSocMed).

\section{References}

Benoit, W. L., \& Brinson, S. L. (1994). AT\&T: “Apologies are not enough”. Communication Quarterly, 42(1), 75-88. http://doi.org/10.1080/01463379409369915

Bonsón, E., \& Ratkai, M. (2013). A set of metrics to assess stakeholder engagement and social legitimacy on a corporate Facebook page. Online Information Review, 37(5), 803-787. http://dx.doi.org/10.1108/OIR-03-2012-0054

Byrd, S. (2012). Hi fans! Tell us your story! Corporate Communications: An International Journal, 17(3), 241-254. http://doi.org/10.1108/13563281211253502

Chang, H. J. (2015). Facebook uses, boundary spanning activities, and social capital. Studies in Media and Communication, 3(1), 34-46. http://dx.doi.org/10.11114/smc.v3i1.777

Colleoni, E. (2013). CSR communication strategies for organizational legitimacy in social media. Corporate Communications: An International Journal, 18(2), 228-248. http://doi.org/10.1108/13563281311319508 
Coombs, W. T. (2007). Protecting Organization Reputations during a Crisis: The Development and Application of Situational Crisis Communication Theory". Corporate Reputation Review, 10(3), 163-176. http://doi.org/10.1057/palgrave.crr.1550049

Coombs, W. T., \& Holladay, S. J. (2014). How publics react to crisis communication efforts: comparing crisis response reaction across sub-arena. Journal of Communication Management, 18(1), 40-57. http://doi.org/10.1108/JCOM-03-2013-0015

Coombs, W. T., \& Holladay, S. J. (2015). CSR as crisis risk: expanding how we conceptualize the relationship. Corporate Communications: An International Journal, 20(2), 144-162. http://doi.org/10.1108/CCIJ-10-2013-0078

Coombs, W. T., Falkheimer, J., Heide, M., \& Young, P. (2015). Strategic Communication, Social Media and Democracy: the challenge of the digital naturals. London, Routledge.

Cox, D., \& McLeod, S. (2014). Social media marketing and communications strategies for school superintendents. Journal of Educational Administration, 52(6), 850. http://dx.doi.org/10.1108/JEA-11-2012-0117

Curley, C. B., \& Noormohamed, N. A. (2014). Social Media Marketing Effects On Corporate Social Responsibility. Journal of Business \& Economics Research (Online), 12(1), 61-n/a. http://dx.doi.org/10.19030/jber.v12i1.8379

Dekay, S. H. (2012). How large companies react to negative Facebook comments. Corporate Communications: An International Journal, 17(3), 289-299. http://doi.org/10.1108/13563281211253539

Diers, A. R., \& Donohue, J. (2013). Synchronizing crisis responses after a transgression. Journal of Communication Management, 17(3), 252-269. http://doi.org/10.1108/JCOM-04-2012-0030

Fieseler, C., \& Fleck, M. (2013). The Pursuit of Empowerment through Social Media: Structural Social Capital Dynamics in CSR-Blogging. Journal of Business Ethics, 118(4), 759-775. http://doi.org/http://dx.doi.org/10.1007/s10551-013-1959-9

Fischer, E., \& Reuber, A. R., (2011). Social interaction via new social media: (How) can interactions on Twitter affect effectual thinking and behavior? Journal of Business Venturing, 26, 1-18. http://doi.org/10.1016/j.jbusvent.2010.09.002

Frandsen, F., \& Johansen, W. (2008). Towards a multi-vocal approach”. In Communication Directory; Newsletter for Corporate Communications and Public Relations, April 2008, 2-4. Retrieved from http://nordicom.statsbiblioteket.dk/ncom/en/publications/towards-a-multivocal-approach(262645f0-0fc5-11de-9a6 7-000ea68e967b)/export.html

Heath, R. L., \& Nelson, R. A. (1986). Issues management: Corporate public policymaking in an information society. Newbury Park, Sage Publications.

Henderson, A., \& Bowley, R. (2010). Authentic dialogue? The role of "friendship" in a social media recruitment campaign. Journal of Communication Management, 14(3), 237-257. http://doi.org/10.1108/13632541011064517

Keim, M. (2011). Emergent use of Social Media: A New Age of Opportunity for Disaster Resilience. Prehospital and Disaster Medicine, 26(S1), s101. http://doi.org/10.1017/S1049023X11003190

Koenig, N. (2014). Acceptance of Corporate Blogs by Internet Users. Corporate Reputation Review, 17(2), 114-137. http://doi.org/10.1057/crr.2014.3

Kolk, A. (2016). The social responsibility of international business: From ethics and the environment to CSR and sustainable development. Journal of World Business, 51(1), 23-34. http://doi.org/10.1016/j.jwb.2015.08.010

Kombol, M. A. (2014). Uses of Social Media among Selected Labour Unions in Abuja during Nigeria's (January 2012) "Oil Subsidy" Removal Protest. Studies in Media and Communication, 2(1), 102-114. http://dx.doi.org/10.11114/smc.v2i1.401

Kwak, H., Lee, C., Park, H., \& Moon, S. (2010). What is Twitter, a Social Network or a News Media? The International World Wide Web Conference 2010, April 26-30, 2010, Raleigh, North Carolina, USA.

Lee, K., Oh, W., \& Kim, N. (2013). Social Media for Socially Rsponsible Firms: Analysis of Fortune 500's Twitter Profiles and their CSR/CSIR Ratings. Journal of Business Ethics, 118(4), 791-806. http://doi.org/10.1007/s10551-013-1961-2

Lee, M. P. (2008). A review of the theories of corporate social responsibility: its evolutionary path and the road ahead. International Journal of Management Reviews, 10, 5-73. http://dx.doi.org/10.1111/j.1468-2370.2007.00226.x

Li, J., Vishwanath, A., \& Rao, H. R. (2014). Retweeting the Fukushima nuclear radiation disaster. Communications of the Acm., 57(1), 78-85. http://dx.doi.org/ 10.1145/2500881 
Luoma-aho, V. (2015). Understanding Stakeholder Engagement: Faith-holders, Hateholders \& Fakeholders. Research Journal of the Institute for Public Relations, 2(1). Retrieved from http://www.instituteforpr.org/understanding-stakeholder-engagement-faith-holders-hateholders-fakeholders/

Luoma-aho, V., \& Vos, M. (2010). Towards a more dynamic stakeholder model: The role of issue arenas for corporate reputation. Corporate Communication: An International Journal, 15(3), 315-331. http://dx.doi.org/10.1108/13563281011068159

Macnamara, J. (2016). Organizational Listening: The missing Essential in Public Communication. New York, Peter Lang Publishing.

Pang, A., Hassan, N. B. B. A., \& Chong, A. C. Y. (2014). Negotiating crisis in the social media environment. Corporate Communications: An International Journal, 19(1), 96-118. http://doi.org/10.1108/CCIJ-09-2012-0064

Pavitt, H. (2012). No Place to Hide: New technological advances in Web 2.0 and Social Media may force organizations to improve their corporate social responsibility. Social Alternatives, 31(2), 22-26. Retrieved from $\mathrm{http}: / /$ search.informit.com.au/documentSummary;dn=339688882642851;res=IELLCC

Romenti, S., Murtarelli, G., \& Valentini, C. (2014). Organizations' conversations in social media: applying dialogue strategies in times of crises. Corporate Communications: An International Journal, 19(1), 10-33. http://doi.org/10.1108/CCIJ-05-2012-0041

Schultz, F., \& Wehmeier, S. (2010). Institutionalization of corporate social responsibility within corporate communications: Combining institutional, sensemaking and communication perspectives. Corporate Communications: An International Journal, 15(1), 9-29. http://doi.org/10.1108/13563281011016813

Sedereviciute, K., \& Valentini, C. (2011). Towards a More Holistic Stakeholder Analysis Approach. Mapping Known and Undiscovered Stakeholders from Social Media. International Journal of Strategic Communication, 5(4), 221-239. http://doi.org/10.1080/1553118X.2011.592170

Sharma, M. (2012). Corporate social responsibility: Scope, Theoretical framework and use of social media. International Journal of Management Research and Reviews, 2(7), 1226-1236. Retrieved from http://search.proquest.com/docview/1417477928?accountid=11774

Sriramesh, K., Rivera-Sánchez, M., \& Soriano, C. (2013). Websites for stakeholder relations by corporations and non-profits. Journal of Communication Management, 17(2), 122-139. http://doi.org/10.1108/13632541311318738

Van den Hazel, P., Keune, H., Randall, S., Yang, A., Ludlow, D., \& Bartonova, A. (2012). The challenge of social networking in the field of environment and health. Environmental Health, 11(Suppl 1), n/a-S15. http://doi.org/10.1186/1476-069X-11-S1-S15

Vos, M., Schoemaker, H., \& Luoma-aho, V. (2014). Setting the agenda for research on issue arenas. Corporate Communications: An International Journal, 19(2), 200-215. http://dx.doi.org/10.1108/CCIJ-08-2012-0055

Wigley, S., \& Lewis, B. K. (2012). Rules of engagement: practice what you tweet. Public Relations Review, 38(1), 165-167. http://dx.doi.org/10.1016/j.pubrev.2011.08.020

Wright, D. K., \& Hinson, M. D. (2009). An updated look at the impact of social media on public relations practice. Public Relations Journal, 3(2), 1-27. http://dx.doi.org/10.5220/0005892401760187

Zhang, B., \& Vos, M. (2014). Social media monitoring: methods, benefits and difficulties for international companies. Corporate Communications, an International Journal, 19(4), 371-383. http://dx.doi.org/10.1108/CCIJ-07-2013-0044

Zhang, B., \& Vos, M. (2015). How and why some issues spread fast in social media. Online Journal of Communication and Media Technologies, 5(1), 371-383. Retrieved from http://www.ojcmt.net/articles/51/516.pdf

Zhang, B., Veijalainen, J., \& Kotkov, D. (2016). Volkswagen Emission Crisis-Managing Stakeholder Relations on the Web. SCITEPRESS-Science and and Technology Publications, 176-187. http://doi.org/10.5220/0005892401760187

\section{(cc) BY}

This work is licensed under a Creative Commons Attribution 3.0 License. 